\title{
The production of porphyrins from $\delta$-aminolaevulinic acid by Haemophilus parainfluenzae
}

\author{
P. LUPPA, K. JACOB and W. EHRET* \\ Institute of Clinical Chemistry, University Hospital Grosshadern, University of Munich, D-8000 Munich 70 \\ and * Institute of Medical Microbiology and Hygiene, University Hospital, University of Regensburg, D-8400 \\ Regensburg, Germany
}

\begin{abstract}
Summary. Porphyrin production by the haemin-independent Haemophilus parainfluenzae in the diagnostic porphyrin test, which determines the $\mathrm{X}$-factor requirement in Haemophilus spp., was analysed quantitatively by applying modern high-performance liquid chromatographic (HPLC) methods. Ion-pair reversed-phase HPLC enabled the simultaneous separation of all porphyrin intermediates and their isomers of haem biosynthesis produced by the bacteria. The $\mathrm{pH}$-dependence of porphyrin production and the respective composition of the porphyrins within the bacterial cells and in the supernate were investigated. $\mathrm{A} \mathrm{pH}$ optimum of $6.9-8.0$ for the production of porphyrins was found and there were marked differences in the porphyrin profiles at different $\mathrm{pH}$ values.
\end{abstract}

\section{Introduction}

In-vitro growth of members of the genus Haemophilus requires accessory growth factors, namely V-factor (NAD) and X-factor (haemin). For identification of cultures of Haemophilus spp., an accurate and rapid means of determining the $\mathrm{X}$-factor requirement is provided by the porphyrin test, which was first described by Biberstein et al. ${ }^{1}$ This test is based on the observation that haemin-independent Haemophilus strains-like many other bacteria-excrete porphobilinogen (PBG) and porphyrin(ogens), when supplied with $\delta$-aminolaevulinic acid (ALA) due to the presence of enzymes converting ALA into PBG and porphyrinogens, intermediates of haem biosynthesis. ${ }^{2,3}$ Porphyrins are synthesised in bacteria by a tightly controlled process, and production rates are linked to the growth rate. ${ }^{4}$ The haemin-independent strains include $H$. parainfluenzae, $H$. parahaemolyticus, $H$. parasuis, $H$. gallinarum, $H$. degnis and $H$. paraphrophilus. ${ }^{3}$ In contrast, $H$. influenzae and other strains like $H$. suis and $H$. aegyptius require haemin, because of their lack of enzymes in the haem biosynthetic pathway. ${ }^{1}$

The discrimination of $H$. parainfluenzae from $H$. influenzae, a common differential diagnostic problem in the routine laboratory, can be done by the porphyrin test. ${ }^{2} \mathrm{~A}$ positive result is shown by reddish fluorescence at an excitation wavelength of $360 \mathrm{~nm}$ after a 4-h incubation period at $37^{\circ} \mathrm{C}$ in the presence of ALA. The porphyrins produced in this test were identified by Biberstein $e t a l .{ }^{1}$ by use of paper chromatography. They detected uro- and protoporphyrin, as well as

Received 11 Nov. 1992; revised version accepted 23 Feb. 1993. some intermediates representing, probably, coproporphyrin. No additional investigations with more sophisticated chromatographic techniques have been performed until now, either to prove the observations of Biberstein et al. ${ }^{1}$ or to specify the isomer ratios of the respective porphyrins formed.

The aim of our study was to separate and analyse quantitatively the individual porphyrins produced by $H$. parainfluenzae in the porphyrin test. We applied a special chromatographic technique - reversed-phase ion-pair HPLC. This highly selective separation method for the determination of free porphyrin carboxylic acids and their isomers can be achieved in either isocratic or gradient elution modes. ${ }^{5,6}$ The technique has been used successfully for the analysis of porphyrin profiles of clinical material in the diagnosis of porphyrias in man.?

\section{Materials and methods}

\section{Bacterial strains}

H. parainfluenzae (type strain ATCC 33392) was obtained from the American Type Culture Collection, Rockville, MD, and grown on chocolate agar in a moist atmosphere supplemented with $\mathrm{CO}_{2} 5 \%$. For comparison and control, the type strain of $H$. influenzae (ATCC 33391) was used.

\section{Porphyrin test procedure}

Activity of the haemin biosynthetic pathway was analysed by the porphyrin test as described by Kilian. ${ }^{2}$ After pre-incubation on chocolate agar at $37^{\circ} \mathrm{C}$ for $24 \mathrm{~h}, 10$ loopfuls of bacteria were inoculated into the 
substrate solution consisting of $2 \mathrm{~mm} \delta$-aminolaevulinic acid hydrochloride (ALA; Sigma) in $10 \mathrm{ml}$ of $0.8 \mathrm{mM} \mathrm{MgSO}_{4}$ in $0.1 \mathrm{M}$ phosphate buffer, $\mathrm{pH} 6.9$. The reaction mixture was incubated at $37^{\circ} \mathrm{C}$ with slight shaking for $4 \mathrm{~h}$. The characteristic red fluorescence of the positive reaction was examined by exposure to a "Wood's light" UV lamp with a maximal emission at $365 \mathrm{~nm}$.

Modifications of the test were made to study the influence of different $\mathrm{pH}$ values of the reaction mixture on porphyrin production. For this purpose, phosphate buffers with $\mathrm{pH}$ values of $5 \cdot 0,6 \cdot 0,6.9$ and $8 \cdot 0$ were chosen. Controls either with $H$. influenzae or lacking ALA in the reaction mixture, were analysed in parallel for estimating the negative test outcome.

For the analysis of synthesised porphyrinogens, the bacterial suspension was centrifuged at $3000 \mathrm{~g}$ for $10 \mathrm{~min}$. The bacterial pellet was washed twice with phosphate-buffered saline (PBS), pH 6.9.

\section{Determination of bacterial protein content}

The protein content of the bacterial preparations was estimated by the method of Lowry as modified by Peterson $^{8}$ with bovine serum albumin (Sigma) as a standard.

\section{Extraction of porphyrins from cell-free fluids}

Cell-free supernates and the respective washing solutions were combined. Porphyrinogens were oxidised with an aqueous solution of iodine $3 \mathrm{mg}$ and potassium iodide $6 \mathrm{mg}$ in $3 \mathrm{ml}$ of water for $10 \mathrm{~min}$ at room temperature. The surplus iodine was eliminated with sodium thiosulphate and $10 \mathrm{ml}$ of $1.2 \mathrm{M}$ phosphoric acid were added. The porphyrins were adsorbed on a Sep-Pak $\mathrm{C}_{18}$-cartridge (Waters, Eschborn, Germany), ${ }^{9}$ washed with water and eluted with $5 \mathrm{ml}$ of methanol:acetone $(1: 1, \mathrm{v}: \mathrm{v})$. The solvents were removed under vacuum and the isolated porphyrins were dissolved in $1 \mathrm{ml}$ of $60 \mathrm{~mm}$ methanolic tetrabutylammonium phosphate $(\mathrm{pH} 7 \cdot 2)$. After centrifugation at $10000 \mathrm{~g}$ for $2 \mathrm{~min}, 10-50 \mu \mathrm{l}$ of this extract was injected for HPLC analysis.

\section{Extraction of porphyrins from bacterial cells}

Pelleted and washed bacterial cells were freeze-dried for $15 \mathrm{~h}$ under light protection. Further disruption of cells and extraction of porphyrins was done by ultrasonic treatment in three $1-\mathrm{ml}$ portions of $60 \mathrm{~mm}$ methanolic tetrabutylammonium phosphate. Cell debris was removed by centrifugation at $10000 \mathrm{~g}$ for $2 \mathrm{~min}$. The extracts were combined, porphyrinogens were oxidised and processed as described above, and 10-50 $\mu \mathrm{l}$ samples were injected for HPLC analysis.

\section{High-performance liquid chromatography (HPLC)}

Apparatus. The HPLC system consisted of a Model L-6200 liquid chromatograph (Merck-Hitachi,
Darmstadt, Germany) equipped with a gradient elution unit, a Model F-1000 spectrofluorimeter (excitation at $395 \mathrm{~nm}$, emission at $625 \mathrm{~nm}$; MerckHitachi) and a Model D-2500 integrator (MerckHitachi) as system controller and data processor.

Chromatographic conditions. Porphyrins were separated by gradient elution on a LiChrospher RP-18 column (5 $\mu \mathrm{m} ; 125 \mathrm{~mm} \times 4 \mathrm{~mm}$ ID; Merck), which was protected by a LiChroCART guard cartridge (LiChrospher RP-18; $5 \mu \mathrm{m} ; 4 \mathrm{~mm} \times 4 \mathrm{~mm}$ ID; Merck). The multilinear gradient used was slightly modified from that described previously: ${ }^{7}$ the elution programme was started with a mixture of aqueous phosphate buffer (40 mM, pH 5.4) $62 \%$ and organic phase $(12.5 \mathrm{~mm}$ tetrabutylammonium phosphate in methanol, $\mathrm{pH} 7 \cdot 2$ ) $38 \%$ for $5 \mathrm{~min}$, then the organic phase was increased within $15 \mathrm{~min}$ to $50 \%$, then within $5 \mathrm{~min}$ to $65 \%$, then within $25 \mathrm{~min}$ to a final concentration of $90 \%$ organic and $10 \%$ aqueous phase. Subsequently, the organic phase was decreased within $1 \mathrm{~min}$ to $80 \%$, which was maintained for $9 \mathrm{~min}$. Finally, the column was reconditioned for $15 \mathrm{~min}$ with the starting mixture. The individual porphyrins were quantified by an external standard containing a mixture of free porphyrin carboxylic acids and the respective isomers (Porphyrin Products, Logan, UT, USA). The flow rate was set at $1 \mathrm{ml} / \mathrm{min}$.

\section{Results}

The production of porphyrin metabolites excreted by $H$. parainfluenzae under various conditions of the porphyrin test was examined. The conceivable impairment of the determination of porphyrin production rates by a self-condensation of ALA was excluded by measuring porphyrins in the porphyrin test incubation medium when Haemophilus cells were absent. Taking into consideration the lower detection limit of the HPLC method for porphyrins of $0 \cdot 1 \mathrm{pmol} / \mathrm{chromatographic} \mathrm{run,} \mathrm{no} \mathrm{evidence} \mathrm{could} \mathrm{be}$ found for such porphyrin production in the ALAcontaining incubation medium.

\section{Sample preparation}

The extraction of the analytes from the supernates of the incubation medium and from the bacterial cells was evaluated by the procedure described below. Porphyrins dissolved in aqueous phases, e.g., incubation media, can be extracted quantitatively by adsorption on to solid-phase RP-18 materials. ${ }^{9,10}$ The recovery rates of this procedure was checked by adding a standard mixture of porphyrin-free carboxylic acids; recoveries of 93-97\% for uro- and coproporphyrin were found whereas that of protoporphyrin varied from 85 to $90 \%$. Extraction of cell porphyrins was achieved after lyophilisation, by ultrasonic treatment in the presence of methanolic tetrabutylammonium phosphate as the extractant, described previously for faeces. ${ }^{11}$ Recoveries of $94-96 \%$ for uro- and 


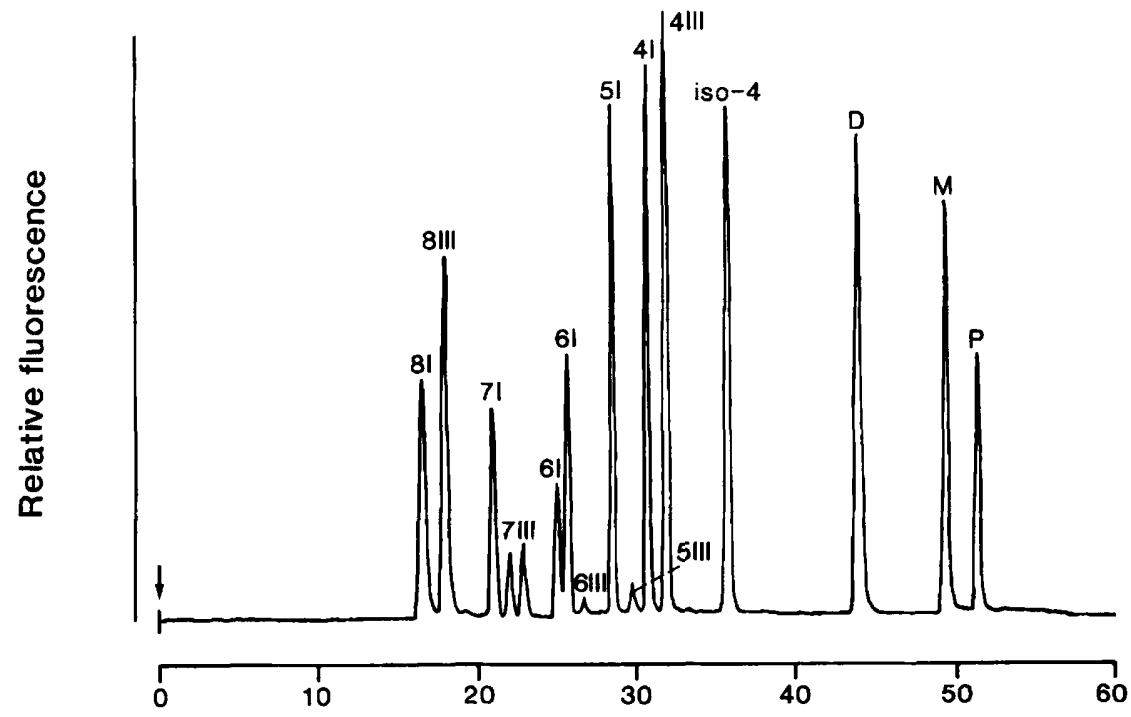

Time ( $\min )$

Fig. 1. Gradient ion-pair HPLC separation of a synthetic mixture of porphyrin isomers on a 5- $\mu \mathrm{m}$ LiChrospher RP-18 column. Mobile phase : multilinear gradient starting with aqueous phosphate buffer $(40 \mathrm{~mm}, \mathrm{pH} 5.4) 62 \%$ and organic phase (12.5 mM tetrabutylammonium phosphate in methanol, $\mathrm{pH} 7 \cdot 2$ ) $38 \%$; final composition after $50 \mathrm{~min}$, aqueous phase $10 \%$ and organic phase $90 \%$. Flow-rate: $1 \cdot 0 \mathrm{ml} / \mathrm{min}$. Abbreviations: 8I, 8III = uroporphyrins I, III ; 7I, III-5I, III = hepta-pentacarboxylic porphyrins I, III ; 4I, 4III = coproporphyrins I, III ; iso-4 = isocoproporphyrin; $\mathbf{D}=$ deuteroporphyrin; $\mathbf{M}=$ mesoporphyrin; $\mathbf{P}=$ protoporphyrin $\mathbf{I X}$.

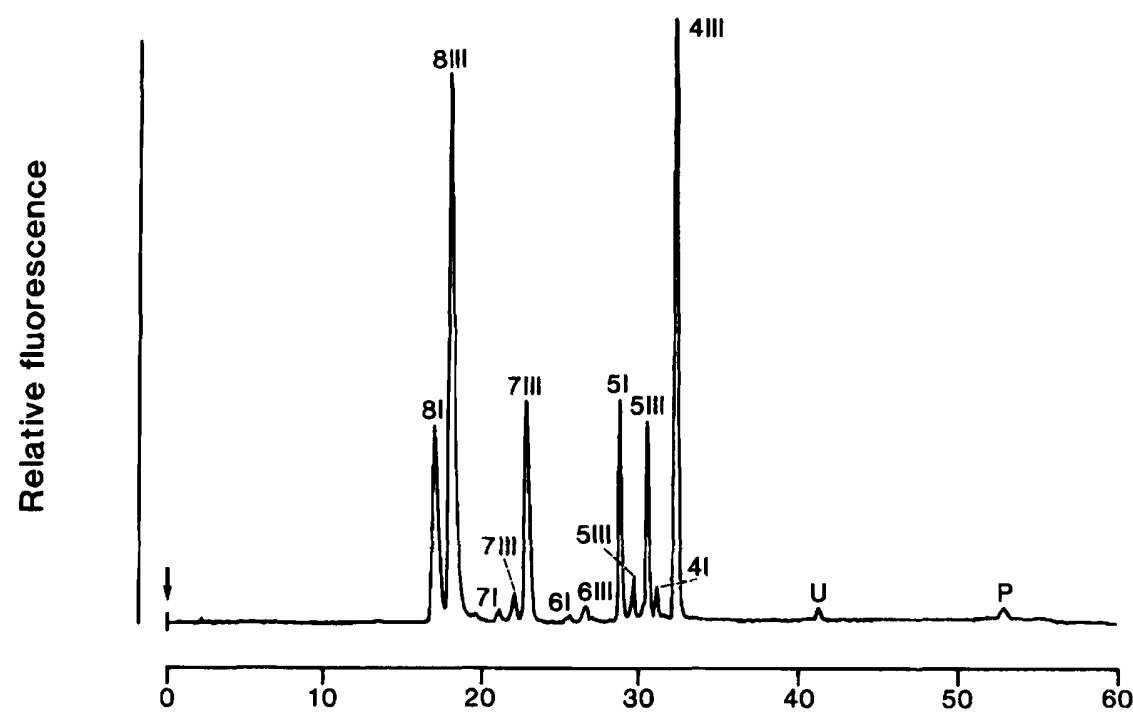

\section{Time (min)}

Fig. 2. Gradient ion-pair HPLC separation of bacterial porphyrins on a 5- $\mu \mathrm{m}$ LiChrospher RP-18 column. The porphyrins were isolated from $H$. parainfluenzae cell lysates of a porphyrin test (incubated at $\mathrm{pH} 6.9$ ). Abbreviations as in fig. $1, \mathrm{U}=$ unknown compound.

coproporphyrin and of $90 \%$ for protoporphyrin were found.

\section{HPLC separation of porphyrins}

Ion-pair reversed-phase HPLC enabled the simultaneous separation of the respective porphyrin isomers I and III in the series from uro- to coproporphyrin including isocopro-, deutero-, meso-, and protoporphyrin in a single chromatographic run (fig. 1). This technique allowed the identification and quantification of all porphyrins formed in the supernates and bacterial cells from the porphyrin test.
The individual porphyrins were positively identified by co-injection of authentic reference compounds. The sample preparation method applied produced clean chromatograms that were not obscured by interfering substances, as shown in the typical chromatograms of a cell lysate (fig. 2) and a supernate (fig. 3).

\section{Porphyrin formation in supernates and cell lysates at various $\mathrm{pH}$ values}

Porphyrin tests with $H$. parainfluenzae were performed at $\mathrm{pH} 5 \cdot 0,6 \cdot 0,6 \cdot 9$ and $8 \cdot 0$. The $\mathrm{pH}$ value of the culture medium had a major impact on porphyrin 


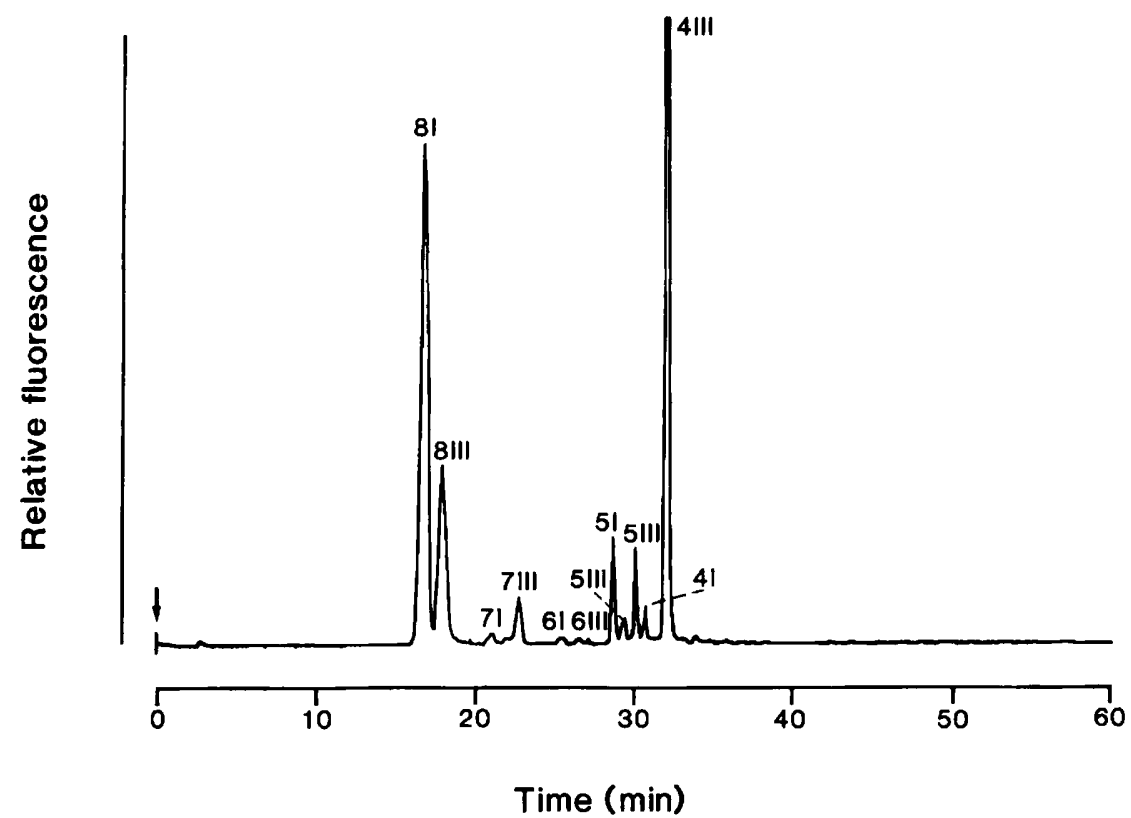

Fig. 3. Gradient ion-pair HPLC separation of bacterial porphyrins on a 5- $\mu \mathrm{m}$ LiChrospher RP-18 column. The porphyrins were isolated from $H$. parainfluenzae culture supernates of a porphyrin test (incubated at $\mathrm{pH} 6.9$ ). Abbreviations as in fig. 1 .

Table I. Porphyrin production from $H$, parainfluenzae in the presence of ALA

\begin{tabular}{|c|c|c|c|c|c|c|c|c|c|c|}
\hline \multirow{2}{*}{$\mathrm{pH}$} & \multirow{2}{*}{ Material } & \multicolumn{9}{|c|}{ Porphyrin production rates $(\mathrm{pmol} / \mathrm{mg} \text { of protein } / 4 \mathrm{~h})^{*}$} \\
\hline & & Uro I & Uro III & Hepta III & Penta I & Penta III & Copro I & Copro III & Proto & Sum \\
\hline \multirow[t]{3}{*}{$5 \cdot 0$} & Lysates & 0.5 & - & - & - & - & $2 \cdot 9$ & 5.0 & $1 \cdot 0$ & $9 \cdot 4$ \\
\hline & Supernates & $0 \cdot 3$ & - & - & - & - & $3 \cdot 6$ & $5 \cdot 8$ & - & $9 \cdot 7$ \\
\hline & Sum & 0.8 & - & - & - & - & $6 \cdot 5$ & $10 \cdot 8$ & 1.0 & $19 \cdot 1$ \\
\hline \multirow[t]{3}{*}{$6 \cdot 0$} & Lysates & - & - & - & 0.4 & 0.5 & $12 \cdot 1$ & $21 \cdot 1$ & $2 \cdot 8$ & $36 \cdot 9$ \\
\hline & Supernates & $1 \cdot 4$ & - & - & $0 \cdot 3$ & $0 \cdot 3$ & 17.5 & $36 \cdot 2$ & - & $55 \cdot 7$ \\
\hline & Sum & $1 \cdot 4$ & - & - & 0.7 & $0 \cdot 8$ & $29 \cdot 6$ & $57 \cdot 3$ & $2 \cdot 8$ & $92 \cdot 6$ \\
\hline \multirow[t]{3}{*}{6.9} & Lysates & $133 \cdot 2$ & $389 \cdot 4$ & $99 \cdot 4$ & $50 \cdot 6$ & $42 \cdot 9$ & $13 \cdot 1$ & $186 \cdot 5$ & 1.9 & 917.0 \\
\hline & Supernates & $240 \cdot 9$ & $97 \cdot 1$ & $17 \cdot 7$ & $19 \cdot 9$ & $16 \cdot 9$ & 6.5 & 148.0 & - & 547.0 \\
\hline & Sum & $374 \cdot 1$ & $486 \cdot 5$ & $117 \cdot 1$ & $70 \cdot 5$ & $59 \cdot 8$ & $19 \cdot 6$ & 334.5 & 1.9 & $1464 \cdot 0$ \\
\hline \multirow[t]{3}{*}{$8 \cdot 0$} & Lysates & $61 \cdot 1$ & $168 \cdot 9$ & $98 \cdot 2$ & $64 \cdot 9$ & $56 \cdot 1$ & $3 \cdot 2$ & 594.8 & $10 \cdot 6$ & $1057 \cdot 8$ \\
\hline & Supernates & $85 \cdot 2$ & $41 \cdot 2$ & 16.6 & $19 \cdot 8$ & 23.9 & $2 \cdot 9$ & 174.7 & - & $364 \cdot 3$ \\
\hline & Sum & $146 \cdot 3$ & $210 \cdot 1$ & 114.8 & $84 \cdot 7$ & $80 \cdot 0$ & $6 \cdot 1$ & $769 \cdot 5$ & $10 \cdot 6$ & $1422 \cdot 1$ \\
\hline
\end{tabular}

Uro, uroporphyrin; Hepta, heptacarboxyporphyrin; Penta, pentacarboxyporphyrin; Copro, coproporphyrin; Proto, protoporphyrin. * All values are means from duplicate tests.

production rates and composition. Tables I and II summarise the porphyrin production rates, given as $\mathrm{pmol} / \mathrm{mg}$ of protein $/ 4 \mathrm{~h}$, for cell lysates, supernates and totals in the presence and absence of ALA. Porphyrin formation in the absence of ALA was sharply reduced at $\mathrm{pH} 5.0-6.9$, whereas at $\mathrm{pH} 8.0$ a marked increase was found. Under these conditions only coproporphyrins I and III, together with protoporphyrin IX, were synthesised (table II). In contrast, porphyrin formation in the presence of ALA is high at pH 6.9 and 8.0 , as expected. Substantially lower production rates were observed at $\mathrm{pH} 5.0$ and 6.0 (table I). The predominantly formed fractions were uroporphyrin I and III, heptacarboxyporphyrin III, pentacarboxyporphyrin I and III and coproporphyrin III. Coproporphyrin I, hexacarboxyporphyrin I and III (not shown) and protoprophyrin IX were observed only in trace amounts.
When the total amounts of porphyrins of cell lysates and supernates were related to the protein content of the bacterial cells, the production rates were increased approximately 10 -fold at $\mathrm{pH} 6.9$ and 8.0 in the presence of ALA compared with those of the ALA-free porphyrin tests (tables I and II). Without ALA the majority of these porphyrins was found in the cell lysates and not in the supernates, whereas in the presence of ALA, substantial amounts of porphyrins were detectable in the supernates.

When the molar ratios of the porphyrins are considered, c. $80-90 \%$ of the total porphyrins formed in the absence of ALA consisted of coproporphyrin III, with coproporphyrin I and protoporphyrin IX as the remainder. At $\mathrm{pH} 8.0$ the proportion of these latter two porphyrins was decreased significantly (table II). No other porphyrins could be detected. In the presence of ALA, the pattern of the porphyrins formed was 
Table II. Porphyrin production from $H$. parainfluenzae in the absence of ALA

\begin{tabular}{|c|c|c|c|c|c|c|c|c|c|c|}
\hline \multirow{2}{*}{$\mathrm{pH}$} & \multirow{2}{*}{ Material } & \multicolumn{9}{|c|}{ Porphyrin production rates $(\mathrm{pmol} / \mathrm{mg} \text { of protein } / 4 \mathrm{~h})^{*}$} \\
\hline & & Uro I & Uro III & Hepta III & Penta I & Penta III & Copro I & Copro III & Proto & Sum \\
\hline \multirow[t]{3}{*}{$5 \cdot 0$} & Lysates & - & - & - & - & - & $0 \cdot 7$ & $11 \cdot 1$ & $3 \cdot 3$ & $15 \cdot 1$ \\
\hline & Supernates & - & - & - & - & - & $0 \cdot 6$ & $5 \cdot 2$ & - & $5 \cdot 8$ \\
\hline & Sum & - & - & - & - & - & 1.3 & 16.3 & 3.3 & 20.9 \\
\hline \multirow[t]{3}{*}{$6 \cdot 0$} & Lysates & - & - & - & - & - & 0.4 & $11 \cdot 7$ & $3 \cdot 4$ & $15 \cdot 5$ \\
\hline & Supernates & - & - & - & - & - & $0 \cdot 7$ & $9 \cdot 2$ & - & $9 \cdot 9$ \\
\hline & Sum & - & - & - & - & - & $1 \cdot 1$ & $20 \cdot 9$ & $3 \cdot 4$ & $25 \cdot 4$ \\
\hline \multirow[t]{3}{*}{$6 \cdot 9$} & Lysates & - & - & - & - & - & $1 \cdot 1$ & $14 \cdot 2$ & $0 \cdot 6$ & $15 \cdot 9$ \\
\hline & Supernates & - & - & - & - & - & 0.5 & $3 \cdot 3$ & - & $3 \cdot 8$ \\
\hline & Sum & - & - & - & - & - & $1 \cdot 6$ & $17 \cdot 5$ & $0 \cdot 6$ & $19 \cdot 7$ \\
\hline \multirow[t]{3}{*}{$8 \cdot 0$} & Lysates & - & - & - & - & - & $1 \cdot 2$ & $138 \cdot 0$ & $1 \cdot 4$ & $140 \cdot 6$ \\
\hline & Supernates & - & - & - & - & - & 0.5 & $20 \cdot 3$ & - & $20 \cdot 8$ \\
\hline & Sum & - & - & - & - & - & $1 \cdot 7$ & $158 \cdot 3$ & $1 \cdot 4$ & $161 \cdot 4$ \\
\hline
\end{tabular}

Uro, uroporphyrin; Hepta, heptacarboxyporphyrin; Penta, pentacarboxyporphyrin; Copro, coproporphyrin; Proto, protoporphyrin.

*All values are means from duplicate tests.

totally different. From table I, it can be deduced that the more polar uro-, hepta- and pentacarboxyporphyrins were formed preferentially at $\mathrm{pH} 6.9$ and 8.0 with a marked reduction of the coproporphyrin isomer I. In contrast, the less polar coproporphyrins I and III, as well as protoporphyrin IX, were increased at $\mathrm{pH} 5 \cdot 0$ and $6 \cdot 0$.

\section{Discussion}

Application of efficient extraction techniques allowed nearly quantitative recovery rates of porphyrins produced within the cells of $H$. parainfluenzae or excreted into the incubation medium. By combining these techniques with a highly selective and sensitive paired-ion HPLC separation method, the complete analysis and identification of all porphyrins and the respective isomers formed in the porphyrin test was achieved for the first time. Our results indicate that in this test various porphyrins are produced by $H$. parainfluenzae in the presence of ALA.

The production of porphyrins within the bacterial cells and their secretion into the culture medium was strongly augmented in the presence of ALA (tables I and II). At pH 6.9 the concentration of coproporphyrin I was increased 12-fold, of coproporphyrin III 19-fold and of protoporphyrin three-fold. The composition of the porphyrins produced depended on whether ALA was present in the incubation medium: porphyrins of the series from uro-, hepta- to pentacarboxyporphyrin were detected only in the presence of ALA and the ratio of coproporphyrin III:I was $17: 1$ at $\mathrm{pH} 6.9$, compared with a ratio of $11: 1$ in the absence of ALA. The unknown porphyrin metabolite (see fig. 2), present in minor concentrations, is possibly identical with pempto- or harderoporphyrin, as mentioned by Brazier. ${ }^{12}$

As shown in tables I and II, the porphyrins at $\mathrm{pH} 6.9$ were predominantly intracellular in the absence of
ALA. In the presence of ALA, increased porphyrin concentrations were found in the cell lysates and were secreted into the culture medium at comparable levels. This points to a limited storage capacity of the bacteria, enabling the detection of porphyrins in the culture medium by UV-fluorescence even with insensitive visual methods.

The $\mathrm{pH}$-dependence of porphyrin production in the porphyrin test was demonstrated by the molar ratios of the individual porphyrins from cell lysates plus supernates. At $\mathrm{pH}$ values below 6.9, the ALA-independent, endogenous production of porphyrins was low, due to the reduced activity of the haem biosynthesis enzymes. Furthermore, the above mentioned variation in the porphyrin composition was observed at pH 6.9 and 8.0 only in the presence of ALA. The production of uro-, hepta- and pentacarboxyporphyrin isomers was made possible at the expense of coproporphyrin III (molar percentage in the absence of ALA was about $90 \%$ whereas in the presence of ALA it was 25-55\%). The lowered molar percentage of coproporphyrin I at $\mathrm{pH} 8.0$ can be explained by a strongly decreased non-enzymic rearrangement of coproporphyrinogen III. ${ }^{13,14}$

Detailed porphyrin analyses are found rarely in the microbiology literature. Previously, Brazier ${ }^{12}$ used HPLC techniques for the analysis of the porphyrin content of fluorescent compounds of pus. Keithly and Nadler ${ }^{15}$ determined the protoporphyrin formation in Rhizobium japonicum by thin-layer chromatographic techniques and found protoporphyrin IX, uro- and coproporphyrin in similar amounts when these bacteria were incubated aerobically. In contrast, Kjeldstad et al. ${ }^{16}$ stated that, in Propionibacterium acnes, coproporphyrin was the predominant porphyrin derivative, whereas protoporphyrin was formed in varying amounts depending on growth conditions.

According to Biberstein et al., ${ }^{1}$ uro- and protoporphyrin are the prevailing porphyrins in Haemophilus spp. in the porphyrin test. This striking difference from our findings can be explained by the 
application of modern, high-resolution analytical methods combined with improved sample processing techniques.

Comparison of the pattern of porphyrin derivatives produced by $H$. parainfluenzae with urinary porphyrins found in patients suffering from acute intermittent porphyria (AIP) reveals remarkable similarities $;^{7.9}$ it seems that the high concentration of the porphyrin precursor porphobilinogen formed by $H$. parainfluenzae in the porphyrin test, leads to a porphyrin metabolism analogous to that observed in AIP.

\section{References}

1. Biberstein EL, Mini PD, Gills MG. Action of Haemophilus cultures on $\delta$-aminolevulinic acid. $J$ Bacteriol $1963 ; 86$ : 814-819.

2. Kilian M. A rapid method for the differentiation of Haemophilus strains. The porphyrin test. Acta Pathol Microbiol Scand [B] $1974 ; 82: 835-842$.

3. Kilian M. Haemophilus. In: Lennette EH, Barlows A, Hausler WJ, Shadomy HJ (eds) Manual of clinical microbiology, 4th edn. Washington, DC, American Society for Microbiology. 1985: 387-393.

4. Bogorad L. Biosynthesis of porphyrins. In: Dolphin D (ed) The porphyrins, vol. VI, part A. New York, Academic Press. 1979: 125-178

5. Jacob K. Porphyrins. In: Heftmann E (ed) Chromatography, part B, 5th edn. Amsterdam, Elsevier. 1992: B335-B362.

6. Jacob K, Sommer W, Meyer HD, Vogt W. Ion-pair highperformance liquid chromatographic separation of porphyrin isomers. J Chromatogr 1985; 349: 283-293.

7. Jacob K, Luppa P. Application of ion pair high performance liquid chromatography to the analysis of porphyrins in clinical samples. Biomed Chromatogr 1991; 5: 122-127.

8. Peterson GL. A simplification of the protein assay method of Lowry et al. which is more generally applicable. Anal Biochem 1977; 83: 346-356.
Additional studies should be performed to elucidate whether our chromatographic technique is able to characterise porphyrin profiles from other bacterial species. The capability of porphyrin formation is not an exclusive feature of Haemophilus spp. as shown by Doss and Philipp-Dormston. ${ }^{17}$ It is probable that characteristic porphyrin profiles could be found in different bacterial species and this may be helpful in the identification of bacteria from clinical samples.

This work was supported by the Hans-Fischer-Gesellschaft (Munich, Germany). The skilful technical assistance of Mrs G. Anding, $\mathrm{Mr} \mathrm{E}$. Egeler and $\mathrm{Mr} \mathrm{B}$. Hennel is gratefully acknowledged.

9. Lim CK, Li F, Peters TJ. High-performance liquid chromatography of porphyrins. J Chromatogr 1988; 429 : 123-153.

10. Jacob K, Egeler E, Hennel B, Luppa P. Coproporphyrin isomers II and IV are normal constituents of human urine. $J$ Clin Chem Clin Biochem 1989; 27: 659-661.

11. Meyer HD, Jacob K, Vogt W, Knedel M. Analysis of free stool porphyrins by high-performance liquid chromatography. $J$ Chromatogr 1981; 217: 473-478.

12. Brazier JS. Analysis of the porphyrin content of fluorescent pus by absorption spectrophotometry and high performance liquid chromatography. J Med Microbiol 1990; 33: 29-34.

13. Mauzerall $D$. The thermodynamic stability of porphyrinogens. $J$ Am Chem Soc 1960; 82: 2601-2605.

14. Jacob K, Egeler E, Hennel B, Luppa P, Neumeier D. The isomer ratios of urinary coproporphyrins I-IV are $\mathrm{pH}$-dependent. Eur J Clin Chem Clin Biochem 1991; 29: 115-119.

15. Keithly JH, Nadler KD. Protoporphyrin formation in Rhizobium japonicum. J Bacteriol 1983; 154: 838-845.

16. Kjeldstad B, Johnsson A, Sandberg S. Influence of $\mathrm{pH}$ on porphyrin production in Propionibacterium acnes. Arch Dermatol Res 1984; 276: 396400.

17. Doss M, Philipp-Dormston K. Porphyrin and heme biosynthesis from endogenous and exogenous $\delta$ aminolevulinic acid in Escherichia coli, Pseudomonas aeruginosa, and Achromobacter metalcaligenes. HoppeSeyler's Z Physiol Chem 1971; 352: 725-733. 